\title{
Einige seltene Schlupfwespen aus Bremens Umgegend.
}

\author{
Von \\ K. Pfankuch, Bremen.
}

Im Laufe mehrerer Jahre ist es mir gelungen, eine Reihe seltener Schlupfwespen in hiesiger Gegend aufzufinden. Die Otte, an denen ich vorzugsweise sammelte, waren: die Badener Berge, der Hasbruch, der Stüher Wald, die Heide bei Immer und Syke. Die aufgeführten Ichneumoniden sind teils im Fluge erhascht, teils von Blüten und Büschen mit dem Fangnetze abgestreift. Nur die zweite Art habe ich erziehen und deren Wirt bestimmen können. Die Blütenpflanzen, welche von Schlupfwespen gern besucht werden, sind: Anthriscus silvestris, Sium latifolium, Cicuta virosa, Daucus Carota und Euphorbia Esula. Diese Pflanzen liefern den Tieren reichlich Honig, der hier offen zu Tage liegt und bei dessen Einsammeln die Schlupfwespen oftmals so eifrig sind, dass man sie mit den Fingern abzuheben vermag. Bei ruhigem, warmem Wetter liefern daher die genannten Blütenpflanzen stets eine gute Ausbeute. Aber auch von den jungen Blättern der Buchen und Eichen kann man durch Abstreifen gar manche Schlupfwespe erwerben.

Ich führe im ganzen 7 Arten vor:

\section{Gravenhorstia picta Boie.}

ð, am 24. 5. 1904 auf der Heide beim Bahnhofe Immer gefangen. Das hübsche Tier hat eine Länge von $25 \mathrm{~mm}$; sein gelbgebänderter Hinterleib ist von der Seite her zusammengedrückt wie bei der bekannten Gattung Ophion F. Es schmarotzt wahrscheinlich in den Raupen von Bombyx quercus oder rubi. Diese Art ist mehr im Süden. Prof. Schmiedeknecht schreibt, dass er sie einmal in Anzahl auf den riesigen Dolden der Ferula auf der Ruinenstätte des alten Karthago angetroffen habe; als nördlichsten Fundort gibt er Hamburg an. Die Gattung ist nach dem verdienstvollen Breslauer Professor Gravenhorst benannt, der 1829 das grundlegende W'erk, die Ichneumonologia Europaea, veröffentlichte. 


\section{Caenocryptus remex Tschek.}

2 오 im Mai 1902 aus Puppen erzogen, die in hohlen Zweigen von Cornus alba L. sich vorfanden. Der Strauch steht in meinem elterlichen Garten hierselbst an der Warturmer Chaussee. Der Wirt ist Psen atratus Panz. (Näheres siehe „Zeitschrift für Hym. u. Dipt.", herausgegeb. von Konow, Teschendorf, Heft 4, 1904.)

Es ist mir bislang noch nicht gelungen, das Männchen aufzufinden. Thomson beschreibt in seiner Opuscula Entomologica auch nur das Weibchen. In den beiden letzten Jahren fanden sich beim Nachsuchen der Cornus-Zweige keine Puppen wieder; ich wäre daher recht dankbar, falls irgend jemand mir in dieser Angelegenheit mit Material aus hiesiger Gegend zur Hand gehen könnte.

\section{Xylophrurus brevicornis Brischke.}

+ , eine Cryptine, einen Übergang zur Xorides-Gruppe bildend. Körperlänge $13 \mathrm{~mm}$, Länge der Bohrerklappen $7 \mathrm{~mm}$. Diese Art scheint recht selten zu sein. Leider vermag ich die Fangzeit und den genauen Fundort nicht anzugeben. Schmiedeknecht führt in seiner Opusc. ichneum. Band VI (1904) diese Spezies als „sehr fraglich" auf, doch ist sie ohne Zweifel eine gute Art. Brischke, der sie in seinem Werke: „Die Hymenopteren der Prov. Preussen“ (Königsberg, 1864) beschreibt, erhielt sie von der Frischen Nehrung.

\section{Medophron niger Brischke.}

우, eine Phygadeuonine, am 1.6.1904 gefangen. Dieses kleine, $7 \mathrm{~mm}$ lange Tier fing ich $\mathrm{zwischen}$ blühenden Anthriscus silvestris am Schutzdeiche hier. Es fällt durch seine schwarze Körperfarbe und den glänzenden Hinterleib auf. Eine Beschreibung finde ich nur in Brischkes Werk "Die Ichneumoniden der Prov. West- und Ostpreussen (Danzig, 1881) vor. Der Verfasser gibt hierin die Bohrerlänge als „kürzer als $1 / 2$ Abdomen" an. Das ist offenbar nicht richtig, denn die Bohrerklappen haben bei meinem Exemplare, das sonst ganz und gar der Beschreibung entspricht, eine Länge von $\mathbf{3} / 4$ des Hinterleibes. Die Gattung Medophron Först. unterscheidet sich von den Verwandten durch das grosse dritte Hinterleibssegment, dessen Länge diejenige des zweiten übertrifft. Wirt unbekannt.

\section{Stilhops vetula Grav.}

$\sigma^{\top}+$, eine Pimpline, 6-7 $\mathrm{mm}$ lang. Ich erhalte diese Art immer im Mai durch Abstreifen der jungen Buchenblätter mit dem Fangnetze. Oft schwirren diese Tierchen auch um die Blätter herum (23. Mai 1902 im Tiergarten bei Delmenhorst, 1903 ebenda, 14. Mai 1904 im Stenumer Gehölz). Wirt nicht bekannt. Die Gattung Stilbops steht der Gattung Pimpla F. nahe; sie unterscheidet sich von ihr insbesondere durch das fast vollkommen gefelderte Mittelsegment. 


\section{Stilbops limneriaeformis Schmiedekn.}

o , $5 \mathrm{~mm}$ lang. Schmiedeknecht gibt in seiner "Revision der europäischen und benachbarten Arten der Ichneumoniden-Gattung Pimpla" nur die Beschreibung des Weibchens, das Männchen führt er als „unbekannt" auf. Die von mir erbeuteten Exemplare sind ohne Zweifel die dazu gehörigen Männchen. Ich lasse daher eine Beschreibung folgen.

Körper zart; Kopf glatt, Gesicht schwächer behaart als bei St. vetula Grav.; Fühler braunschwarz, nach der Basis hin unterseits lichter, Schaft unten weisslich. Vorderleib wie beim Weibchen, nur die Felderung des Mittelsegmentes etwas mehr hervortretend. Hinterleib etwas schmaler als der Vorderleib; schwarz; dicht, aber seicht punktiert, schwach glänzend, die vorderen Segmente gelblich gerändert. Das erste Segment hinter der Mitte mit einem Quereindruck, dahinter höckerartig erhaben; das zweite und dritte Segment mit Beulen, die nahe am Rande gelegenen Luftlöcher derselben hervortretend. Flügel irisierend, wasserhell, Flügelschuppen weisslich, Stigma gross und breit, hellrotgelb, Unterrand dunkel. Beine gelblichweiss; rotgelb gefärbt sind: die Hinterhüften (ausgenommen die gelblichweisse Spitze) und die Hinterschenkel; braunschwarz: die Spitze der Hinterschienen, die Hintertarsen (die obere Hälfte des Metatarsus ist hell) und alle Klauen mit den Haftläppchen. Auch dieses Tier fing ich auf Buchenblättern, zusammen mit der vorigen Art. Merkwürdigerweise ist mir das Weibchen noch nicht vorgekommen. Wirt unbekannt.

\section{Ctenopelma Braunsii n. sp.}

$\sigma^{\star}$ 오. Dieses hübsche, schwarzglänzende Tier steckte lange Zeit unbestimmt in meiner Sammlung. Bei einer Sendung an Prof. Brauns in Schwerin gab ich es mit und dieser erkannte es als eine reue Art. Da eine Beschreibung noch nicht veröffentlicht worden ist, so gebe ich sie im folgenden.

Glänzend, der ganze Körper mit weitstehenden, grossen Punkten, aus denen die langen, abstehenden, greisen Haare hervorragen. Kopf hinter den Augen etwas verschmälert, Scheitel bläulich bereift, hinterwärts breit ausgerandet; der vordere grössere Teil des Kopfschildes herabgebogen, unterer Zahn der Oberkiefer etwas länger als der obere; Fühler kräftig, fadenförmig, behaart, fast von Körperlänge, zwischen den Gliedern mit dunklen Querlinien, nach der Basis hin wenig verschmälert; Gesicht lederartig. - Vorderleib höckerig, Mittelrücken bläulich bereift, mit Rückenfurchen (beim 오 schwach), Schildchen bis zur Mitte scharf gerandet; Mittelsegment mit 2 Längsleisten, die area basalis und die area superomedia zasammenfliessend, die letıere und die area posteromedia durch eine gebogene Leiste getrennt. - Hinterleib spindelförmig, das erste Segment ohne Rinne, Bauchfalte beim Männchen gelbrot, beim Weibchen braun; Bohrerklappen $1 \mathrm{~mm}$ lang, schräg aufwärts gerichtet bis zur Höhe des Hinterleibes, ihr Hinterrand schmal gelbrot. 
- Flügel irisierend, schwach getrübt; Stigma braunrot, nach der Basis hin heller; Areola schmal, gestielt, der Aussennerv in der unteren Hälfte erloschen; Nervellus postfurkal, in der Mitte gebrochen. - Beine kräftig, die Schienen steif behaart, die Klauen mit langen und dichten Kammzähnen. Länge $10^{1} / 2 \mathrm{~mm}$, Bohrer $1 \mathrm{~mm}$.

ㅇ schwarz; rotgelb sind: der herabgebogene Teil des Kopfschildes, die Oberkiefer, die Taster, die beiden Scheitelflecke und die Fühler (nach vorn hin mehr bräunlich); an den Vorderbeinen die Spitzen der vorderen Schenkelringe, die Schenkel, Schienen und Tarsen; an den Hinterbeinen: die Knie, die Basishälfte der Schienen, die Sporne und die Basis aller Tarsenglieder. - Die Vorderecken des 3. Segments mit zwei leuchtenden, rotgelben Linien; Flügelschuppen braun.

ot schwarz; gelblichweiss sind: Gesicht, Kopfschild und Fühlerschaft unterwärts, die Oberkiefer, die Taster, jederseits ein Wangenfleck, die beiden Scheitelflecke, der grössere (hintere) Teil des Schildchens, die Flügelschuppen und ein Strich unter denselben; an den Vorderbeinen: die Hüften (Mittelhüften an der Basis schwarz), die Schenkelringe, die Schenkel und die Basis der Schienen; an den Hinterbeinen die Spitze der Hüften, die Schenkelringe (oberseits mit schwarzem Fleck), die Knie, Basis der Schienen, Sporne und die Basis aller Tarsenglieder. Der grösste Teil der Vorderschienen und die Vordertarsen sind hellrotgelb, die untere Hälfte der Hinterschienen und die Hintertarsen bräunlich gefärbt; die beiden letzten Hintertarsenglieder heller. Das 3. Hinterleibssegment ist an der Basis und an den Seiten kastanienbraun gefleckt.

Diese Art steht der Ct. variabilis Tschek am nächsten und zwar der Stammart. Sie weicht von derselben ab durch den Nervellus, der in der Mitte gebrochen ist, durch den kürzeren Bohrer und besonders durch die Färbung. Leider vermag ich den Fundort nicht bestimmt anzugeben, auch nicht die Fangzeit, noch weniger den Wirt.

Ich benenne diese Art zu Ehren von Herrn Prof. S. Brauns in Schwerin. 


\section{$2 \mathrm{BHL}$ Biodiversity Heritage Library}

Pfankuch, K. 1904. "Einige seltene Schlupfwespen aus Bremens Umgegend." Abhandlungen herausgegeben vom Naturwissenschaftlichen Verein zu Bremen 18, 139-142. https://doi.org/10.5962/bhl.part.27527.

View This Item Online: https://www.biodiversitylibrary.org/item/22972

DOI: https://doi.org/10.5962/bhl.part.27527

Permalink: https://www.biodiversitylibrary.org/partpdf/27527

\section{Holding Institution}

New York Botanical Garden, LuEsther T. Mertz Library

\section{Sponsored by}

The LuEsther T Mertz Library, the New York Botanical Garden

\section{Copyright \& Reuse}

Copyright Status: NOT_IN_COPYRIGHT

This document was created from content at the Biodiversity Heritage Library, the world's largest open access digital library for biodiversity literature and archives. Visit BHL at https://www.biodiversitylibrary.org. 